\title{
Modeling of Coal-Fired Power Units with ThermoPower Focussing on Start-Up Process
}

\author{
Sebastian Meinke ${ }^{1}$ Friedrich Gottelt $^{2} \quad$ Martin Müller $^{1} \quad$ Egon Hassel $^{1}$ \\ ${ }^{1}$ University of Rostock, Chair of Thechnical Thermodynamics \\ A.-Einstein-Str. 2, 18059 Rostock, Germany \\ ${ }^{2}$ XRG Simulation, Harburger Schlossstr. 6-12, 21079 Hamburg, Germany \\ sebastian.meinke@uni-rostock.de gottelt@xrg-simulation.de
}

\begin{abstract}
Governmental encouragement of renewable energies like wind energy led to an extensive increase of installed wind energy capacity worldwide. In order to allow a complete integration of this continuously fluctuating energy source, it is necessary to have a highly flexible operation management as well as power stations which are able to follow the high dynamics of the wind power production.

In this context the component fatigue and operational limitations of current and future power stations have to be investigated under the influence of enhanced plant dynamics.

For this purpose a detailed Modelica model of the hard coal fired steam power plant of Rostock, Germany is presented and extensively validated. The model makes use of the well-known non-commercial library ThermoPower. This Modelica Library is extended by models for common solid fuel burners and radiation-dominated firing zones. In addition to this, different approaches for modeling two-phase containers like the feed water tank are discussed. The derived model is used to compare different operation modes with respect to the occurring component wear.
\end{abstract}

Keywords: ThermoPower, coal fired power plants, firing modeling, two phase tank, power unit start up

\section{Introduction}

In a future power grid with high renewable power feed, especially from wind power, it becomes more important as well as economically beneficial for conventional power plants to be able to adjust the production in order to balance the renewable energies. But due to the long life time, the majority of current power plants have been designed decades ago mainly for steady state operation. Consequently, the focus was put more on reliability and preservative operation than on high dynamics.

The recent and ongoing changes in the energy market in Germany will lead to an increased number of start-ups and load changes, which cause additional life time consumption. Improvements of the existing technologies are required to enable higher dynamics at limited additional stress during transient operation.

This is especially true for coal fired power plants because of the fuel pulverization in coal mills. These mills have a slow and often unknown dynamic and limit the load gradient of coal fired units. Additionally, the boiler itself shows a slow transient response due to its big metal and water masses as well as uncertainties like degradation of the heat transfer due to ash build up on the heating surfaces. To overcome this, the load change rates are made sufficiently slow. Improvements to this conservative approach could be achieved by the use of advanced control systems, e.g. state observers and model based control systems or additional sensors, like for example coal dust measurement [1].

For the evaluation of such optimizations of the process and the control system, computer aided simulation of the power plant process could be a powerful tool.

\section{Scope of Investigations and Ther- modynamical Model}

In order to judge the expected impacts of a more dynamic power plant operation a detailed, transient model consisting of one-dimensional or lumped interlinked sub models, based on thermodynamic fundamental equations, is presented. The $550 \mathrm{MW}$ hard coal power plant Rostock, that started its operation in 1994, has been used as a reference. The power plant repre- 
sents the state of the art and is due to its long rest life time heavily effected by future changes of the energy market.

\subsection{Object of Investigation}

The power plant Rostock has a conventional, hard coal fired steam generator. This is a single direction oncethrough forced-flow boiler in Benson design, which is run in modified sliding pressure operation. The boiler is equipped with four superheater and two reheater heating surfaces. The fuel supply is carried out by a coal dust firing with direct injection. The combustion itself takes place in $16 \mathrm{NO}_{x}$-lean vortex staged burners, which are distributed on 4 burner levels with each 2 burners on the front and back side.

The main characteristics are provided in the following table (1):

Table 1: Key data of power unit Rostock, Germany [2]

\begin{tabular}{|l|l|l|}
\hline power unit data & gross electric power & $550 \mathrm{MW}$ \\
& net efficiancy rate & $43.2 \%$ \\
& district heating & $300 \mathrm{MJ} / \mathrm{s}$ \\
& max. degree of utilization & $62 \%$ \\
\hline boiler & manufacturer & Babcock \\
& design & once-through forced-flow boiler \\
& & single direction design \\
& & single reheating \\
& life steam production & $417 \mathrm{~kg} / \mathrm{s}$ \\
& SH-pressure/ -temperature & $262 \mathrm{bar} / 545^{\circ} \mathrm{C}$ \\
& RH-pressure/ -temperature & 53 bar $/ 562{ }^{\circ} \mathrm{C}$ \\
& opposed firing, 4 levels \\
& combined coal dust/oil & 4 roll wheel coal mill MPS 225, \\
& hard coal \\
\hline turbo gen set & coal mills & ABB \\
& mithout regulating wheel \\
& design & $1 \mathrm{HP}, 1 \mathrm{IP}, 2 \mathrm{LP}$ \\
& number of housings & natural/modified sliding pres- \\
& operation mode & sure \\
\hline
\end{tabular}

\subsection{Overview of the Power Plant Model}

Base for this power plant model is the non-commercial Modelica library ThermoPower [3]. Many of the comprised sub models in the ThermoPower library, like pipes, valves, metal walls, mixers, etc. have been used in this work or have been taken as a starting point for self-developed models. One of the newly added models is a generic two phase tank, that can be used for a feed water tank, preheaters, a start bottle or a condenser. Furthermore, models for cyclone separators, a combustion chambers and segments of a flue gas duct have been developed. Two of these new sub models are presented in the following section 3 .

The focus of the investigation has been put on the water-/steam circuit, the combustion chamber of the steam generator and the fresh air passage within the coal mills, as well as their dynamics and the influence of different operation modes on distinct devices e.g. thick-walled headers and turbine shafts.

A simplified schematic of the model is shown in figure 1. Indicated are the feed water pumps, high pressure preheaters (HPP), the steam generator, the different turbine stages, as well as the forced draft and mill fan, the air preheater and the coal mills. The low pressure preheaters (LPP) are not part of the power plant model, since they are not highly stressed, due to their low temperature level.

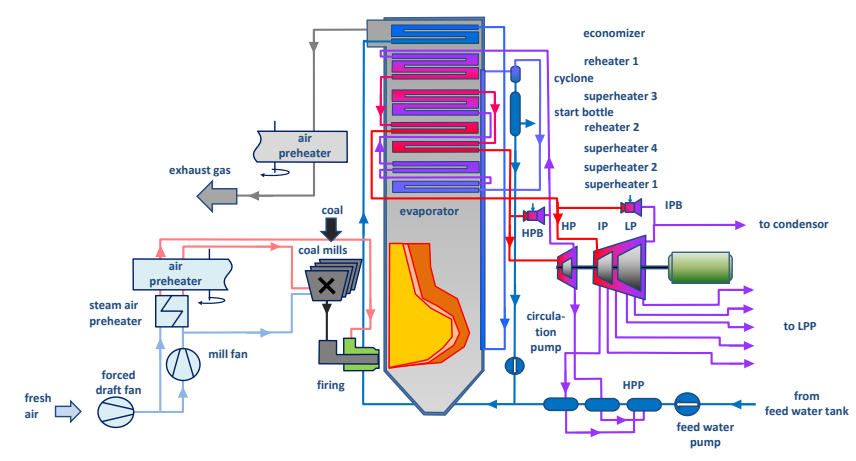

Figure 1: structure of power plant model

For making simulation-based statements about the influence of different power plant operation modes the thermodynamical model is coupled to a reduced copy of the power plant control system, which is implemented using the Modelica Standard Library components.

The implemented control system uses the currently calculated physical values (i.e. live steam parameter, generated power at a specific coal input) and in a consequence adjusts set values (e.g. life steam pressure) and manipulated variables (e.g. rotational speed of the feed water pump) of the water-steam cycle. Because of this feedback the grade of details as well as the accuracy of the modelled steam cycle and its interfaces to the control system needs to be reasonably high.

In detail the power plant control system sets the manipulated values using a map based pilot control. The expected control variable is predicted by a transfer function based model of the process. The difference between this predictive value and the corresponding measurement is adjusted via a corrective control loop, as described in the VDI/VDE guideline 3508 [7].

\subsection{Level of Detail}

In the following the degree of detail is explained by using the detailed reproduced boiler as an example. The boiler model differentiates eight separate heating surfaces: economizer, evaporator, four superheaters and 
two reheaters. Between the superheaters $\mathrm{SH} 1$ and $\mathrm{SH} 2$ as well as SH3 and SH4 plus in between the reheaters $\mathrm{RH} 1$ and $\mathrm{RH} 2$, spray atemperators are located for live steam temperature control.

In compliance with the modular approach of Modelica any of the boiler's eight different heat exchangers is composed of different base models, see figure 2 . Starting from highest temperature components the following modules can be found: The flue channel segment which models the energy storage as well as the gas side heat transfer due to convection and radiation, a sub model, that calculates the conductive heat transfer inside the metal wall of the pipes and a third module for the convective heat transfer occurring at the inner wall as well as a one-dimensional pipe flow model. The heat flow at the system boundary between these modules is implemented using connectors. On the gas side very complex heat and mass transfer conditions occur defined by a large range of temperature and a variety of geometric characteristics. To cope with this complexity semi-empirical heat transfer correlations for the different stages of the combustion chamber can be distiguished while the three-dimensional flow field is reduced to one dimension. The latter reduction neglects any deviations from the perfect symmetric temperature and flow field but is in congruence with the "one-pipe"-approach of the water and steam side of the boiler.

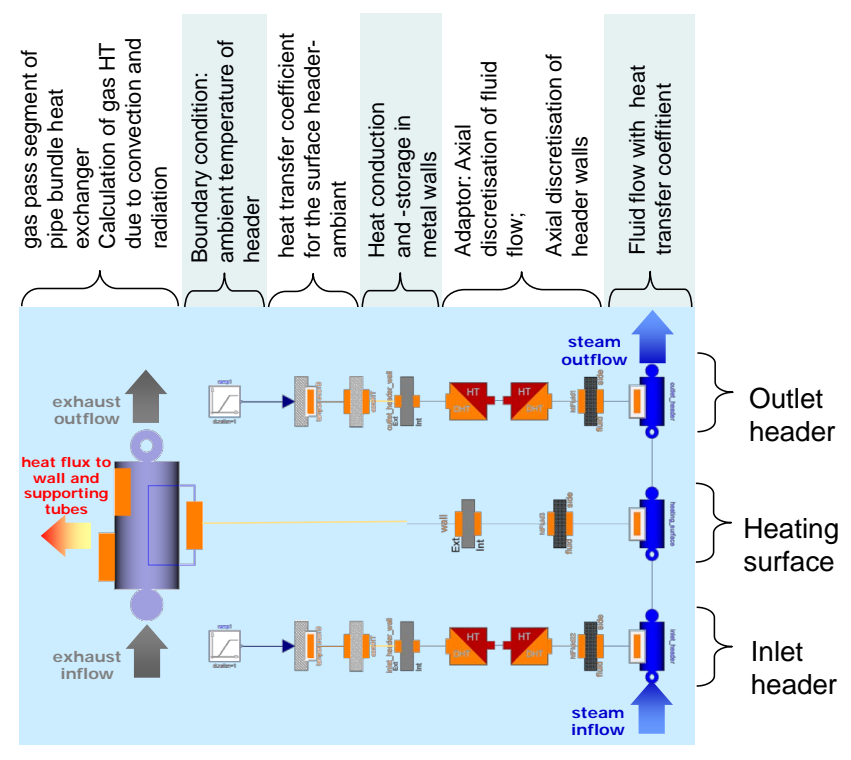

Figure 2: Dymola view of a generic superheater, which distinguishes inlet and outlet header and heating surface

Before and after each of the bundle heat exchangers a thick-walled header is located to allow a mixing of several legs connected in parallel. Again, we find models for convective and conductive heat transfer and energy storage in the metal masses of the surrounding walls. In addition, there are adapter modules to couple components of different dimensionality. This is necessary because the headers are discretisized in flow direction while the thick header walls are discretisized in heat flow direction which is perpendicular to the first mentioned.

\section{Addidtional Components}

In the following chapter a selection of the developed components are presented, section 3.1 explains the sub models for the reproduction of the firing process and gas side heat transfer. In section 3.2 the modeling of a two phase tank is discussed.

\subsection{Modelling of the steam generators gas side}

Due to the complex, unsteady and 3-dimenstional nature of a real firing process, a model of the combustion process, which is a part of an overall power plant model, needs to be strongly simplified. For that reason instant combustion is assumed and subsequently a lumped gas volume model is used for the reproduction of the combustion chamber, which works according to the principle of a homogeneous agitating tub [6] with uniform flue gas conditions (see figure 3).

The main input values for combustion calculation are fuel and fresh air properties. The description of the fuel is conducted by a raw coal composition and the coal mass flow, which is delivered by a coal mill model. The modeling of the coal mills has been done according to work of Niemczyk et al., 2009 [4].

The raw coal composition can be obtained by an elementary analysis and integrates a single ash and embedded water fraction (equation 1). On the gas side the ThermoPower component SourceW was used for generating a combustion air mass flow. To indicate the preheated air conditions the moist air media of Modelica.Media has been applied. The air properties are functions of the boiler load.

The essential of this model is a simple combustion calculation without pollutants. Also implemented are functions for lower heating value according (see equation 2 [5]) and air ratio in dependency of desired firing power.

Other parameters are the ash fraction, which is suspended in the flue gas and the unburnt carbon fraction 


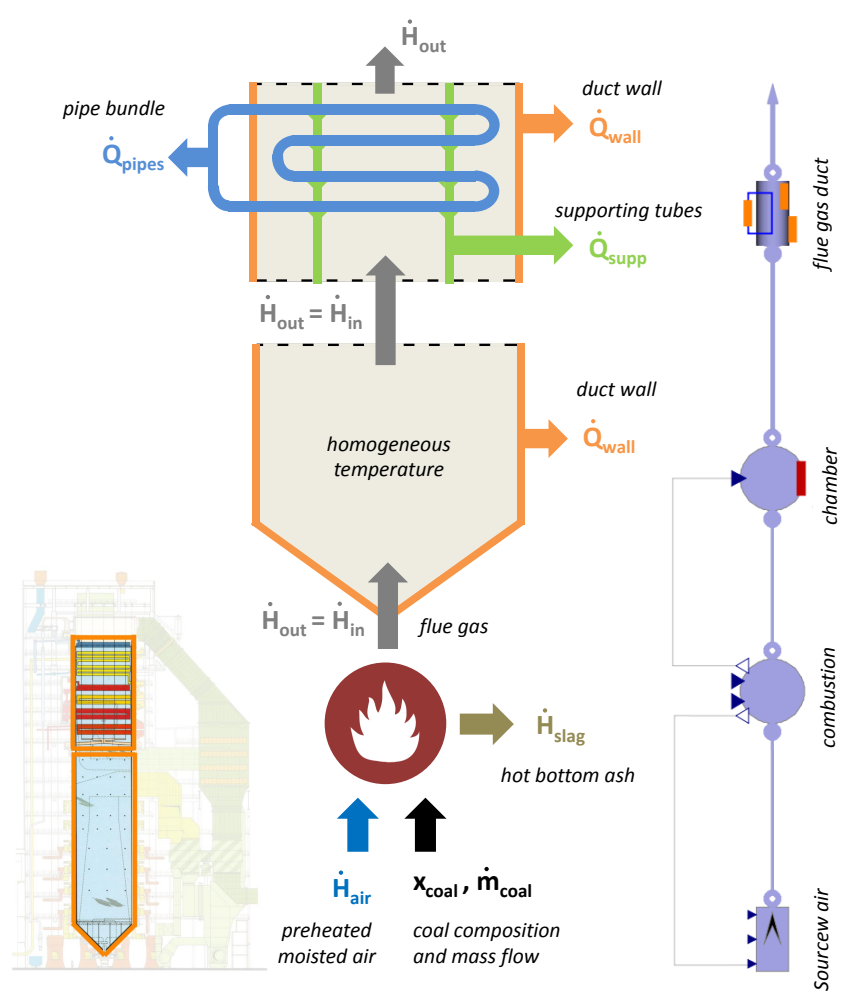

Figure 3: scheme of the combustion chamber and flue gas duct

that remains in the solid ash. This data is important for the particle radiation and is set to default values of 0.90 and 0.02 , respectively. In result of the known energy balance the combustion model creates a flue gas with its adiabatic combustion temperature. Therefore the "simple flue gas" media model was introduced and its properties can be transfered to an output flow connector. (see equation 3 ).

$$
\begin{gathered}
x_{C}+x_{H}+x_{S}+x_{O}+x_{N}+x_{W}+x_{A}=1 \\
H_{u}=\begin{array}{c}
34.8\left(x_{C}-x_{C u}\right)+93.8 x_{H}+10.46 x_{S} \\
+6.28 x_{N}-10.8 x_{O}-2.45 x_{W}
\end{array} \\
x_{i, R G}=\frac{\hat{m}_{i, R G}}{\hat{m}_{R G}}
\end{gathered}
$$

The heat transfer from the flue gas to the different surface areas is caused by two physical mechanisms, radiation and convection. Convection is heat transfer via particle transport and works on all overflowed surfaces. The formula 4 uses a heat transfer coefficient, which depends on the fluid properties, the flow velocity and the geometry of the surface (see equation 5). Every vertical surface (membrane duct wall and the supporting tubes, which are carrying the pipe bundles) is handled like an overflowed plate. The Nusseltnumber is calculated according to [6].

The streaming around the pipe bundle surface is a forced flow across a tube. In this case the Nusseltnumber calculation is extended by a geometrical alignment factor [6]. The used flue gas properties are averaged values between two nodes. For ribbed tubes (economizer) an effective heat transfer coefficient will be computed according to [5], which takes the rib effects into consideration.

$$
\begin{gathered}
\dot{Q}_{\text {conv }}=\alpha_{\text {conv }} \cdot A_{\text {wall }} \cdot\left(T_{\text {gas }}-T_{\text {Wall }}\right) \\
\alpha_{\text {konv }}=\frac{N u \cdot \lambda}{l}
\end{gathered}
$$

Especially in higher temperature regions above $1000{ }^{\circ} \mathrm{C}$ (combustion chamber) the heat radiation is the dominant heat transfer mechanism (see equation 6). The radiation sources are the flue gas, the contained solid particles (dust) and the surfaces. The influences of these three sources are expressed in different dimension free emission $(\varepsilon)$ and absorption $(a)$ coefficients.

In the flue gas only the components $\mathrm{H}_{2} \mathrm{O}$ and $\mathrm{CO}_{2}$ are relevant emitters. The combined emission coefficient of both is calculated using equation 7 [6]. The calculation of the emission coefficients for dust (in fact unburnt carbon and flying ash) is also described in [6]. The implemented functions also consider the back radiation from the wall to the flue gas represented by the absorption coefficients.

$\dot{Q}_{\text {rad }}=\varepsilon_{\text {gas } / \text { wall }} \cdot \sigma \cdot A \cdot\left(\varepsilon_{\text {gas } / \text { dust }} \cdot T_{\text {gas }}^{4}-a_{\text {gas } / \text { dust }} \cdot T_{\text {wall }}^{4}\right)$

$$
\varepsilon_{\text {gas } / \text { wall }}=\frac{\varepsilon_{\text {wall }}}{1-\left(1-a_{\text {gas } / \text { dust }}\right) \cdot\left(1-\varepsilon_{\text {wall }}\right)}
$$

Considering the discharged heat flow to the membrane wall the homogeneous temperature in the combustion chamber is calculated by the energy balance. The main parameter for adjustment is the introduced fouling correction factor. This factor is implemented into the energy balance and represents the fouling of the heat surfaces. The fouling decreases with lower flue gas temperatures.

Subsequently the exhaust gas is flowing to the flue gas duct, which is the second part of the steam generator and located above the combustion chamber. For effective modeling it is divided in segments - one for 
every pipe bundle heat exchanger. Each sub model is based on the 1-dimensional gas flow model of the ThermoPower library. The modified models have three heat transfer ports - one for the flue gas duct wall (evaporator), the supporting tubes (superheater SH 1) and the pipe bundle itself (superheaters, reheater and economizer) - shown in figure 4.

An exception is the superheater $\mathrm{SH} 1$, its pipe bundle is at the lower end of the supporting tubes and the heat transfer will be computed by empiric equations [5]. For every flue section following parameters can be defined: number of nodes, geometry and fouling factor. In cooperation with the other models of the ThermoPower library it is easy to construct direct- or counter-current heat exchangers.
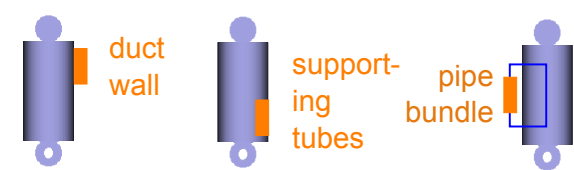

flue gas duct models with different heating surfaces
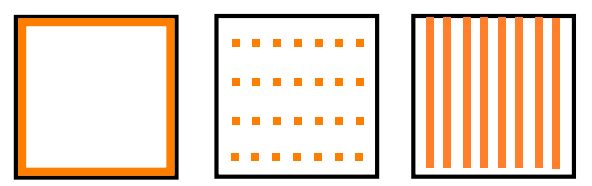

cross section of flue gas duct (top view)

Figure 4: overview of the heating surfaces of the flue gas duct

\subsection{Two-Phase Tank}

In order to decouple the low pressure part from the high pressure part of the water-steam cycle a large storage tank is located between the low pressure preheaters and the feed water pump. This tank typically contains both, steam and liquid water. The two phases interlink to each other by heat and mass transfer. During slow load changes and steady state operation water and steam will be in an equilibrium, i.e. the phases will be near the dew and boiling curve, respectively. Due to limited heat transfer between both phases a constant temperature difference between the phases will arise. In contrast to this, during fast state changes, as they may occur during condensate hold-up, a significant fraction of steam may be present in liquid phase and vice versa. To cope with this effects a model solving energy and mass balance for both phases separately was implemented, using the central equations below. Herein the generic inlet and outlet ports in and out are defined as ThermoPower components flange :

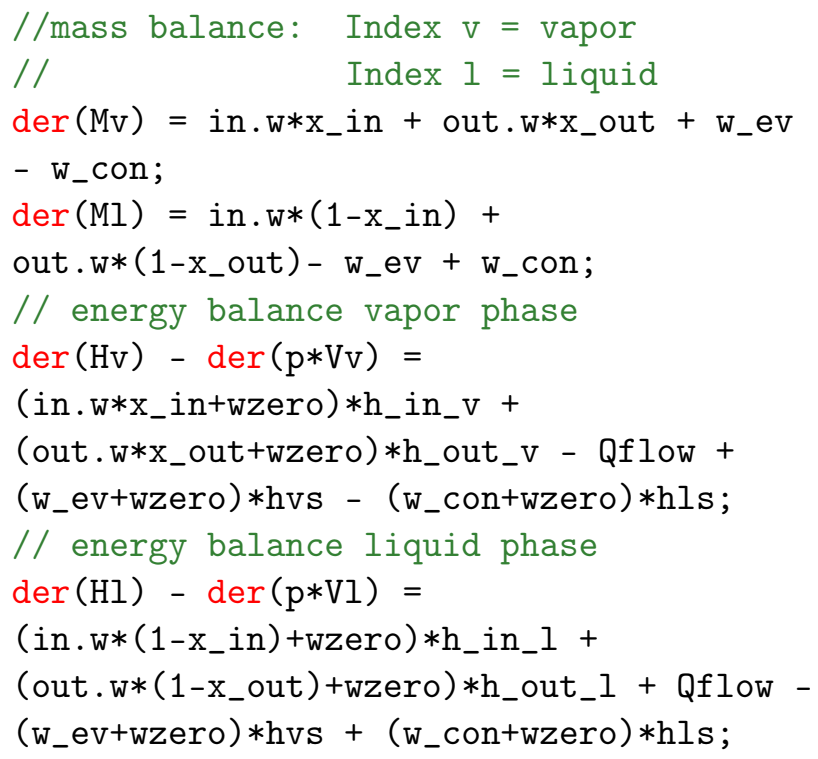

Thereby linking the two phases via the evaporation and condensation mass flow rates and the heat exchange via the common surface:

$\mathrm{w}_{-} \mathrm{ev}=\max (0, \operatorname{tau} *(\mathrm{hl}-\mathrm{hl} \mathrm{s}) /(\mathrm{hvs}-\mathrm{hls}) * \mathrm{Ml})$;

$\mathrm{w}_{\text {_con }}=\max (0$, tau $*(\mathrm{hvs}-\mathrm{hv}) /(\mathrm{hvs}-\mathrm{hl} \mathrm{s}) * \mathrm{Mv})$;

Qflow $=$ Asup*alpha* $(\mathrm{Tv}-\mathrm{Tl}) ; \quad$ The code

omits the heat exchange with the surrounding walls for the sake of simplicity. However, the model makes use of some unknown parameters, namely tau as the time constant for phase change processes and alpha as the heat transfer coefficient (HTC) at phase interface. For this reason a parameter variation was done to gain information about the influence of these parameters.

For evaluation a temporary reduction of the condensate mass flow entering the feed water tank is considered. Usually the condensate flow is controlled to keep the feed water tank level at a defined set value but when short-term generator power is needed the condensate mass flow is reduced thus increasing the turbine mass flow in an indirect manner. This condensate holdup is the state-of-the-art method for primary regulation. The scenario comprehends a reduced condensate mass flow rate over approximately $13 \mathrm{~min}$ starting at $\mathrm{t}=60 \mathrm{~min}$ while a constant mass flow is extruded by the feed water pumps. In consequence the water level decreases, see figure 5. After finishing the condensate holdup the controller starts filling the container again by massively increasing the condensate inflow into the tank. Considering the variation of the heat transfer between the phase interface we find that the time response of the level is not affected by differing interface heat transfer coefficients. In contrast to this the tank pressure is qualitatively and quantitatively influenced by this parameter, see figure 


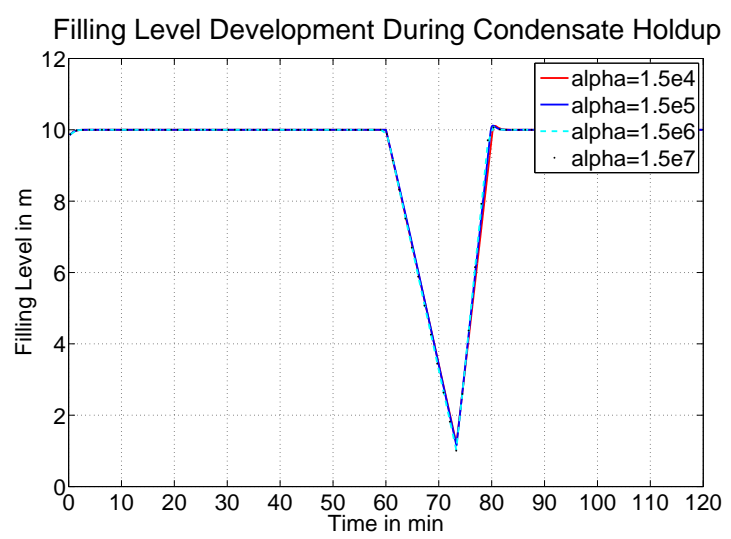

Figure 5: Tank Pressure development during condensate hold-up

6. The stationary tank pressure is lower for cases with near-ideal heat transfer indicated by high heat transfer coefficients $\alpha \geq 1.5 \cdot 10^{7} \mathrm{~W} /\left(\mathrm{m}^{2} \mathrm{~K}\right)$. The scenario with heavily reduced heat transfer leads to decreasing pressures during condensate holdup because the effect of the reduced cooling by the cold condensate is overcompensated by the decompressing effect of the emptying process. For the cases with a high energetic coupling of the two phases we find the cooling effect of the condensate to outweigh the emptying process. The time constants for phase change have a similar phasecoupling impact as the heat transfer but turns out to be quantitatively of minor influence and is therefore not discussed in detail.

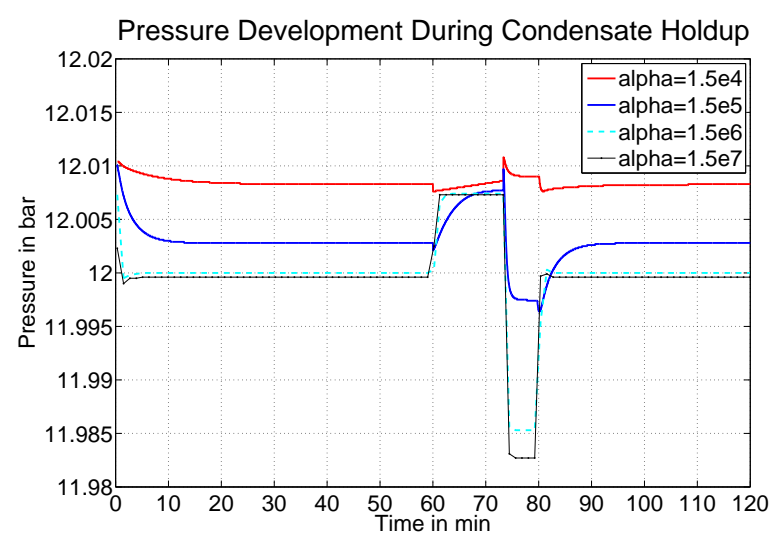

Figure 6: Tank Pressure development during condensate hold-up varying the HTC

The question arising from figure 6 is how intense the heat transfer between the liquid and gaseous phase is. Analysis of continuous measurement data provided by the power plant operator revealed a fairly constant temperature difference between the liquid temperature and the saturation temperature gathered from the tank pressure $\Delta T \approx 3.7 \mathrm{~K}$. This suggests a good heat transfer between the phases referring to a heat transfer coefficient of $\alpha=1.5 \cdot 10^{5} \mathrm{~W} /\left(\mathrm{m}^{2} \mathrm{~K}\right)$. This high heat transfer coefficient, typical for good inter-phase mixing, is ensured by the applied Stork spray injector.

When considering the pressure development and the subcooling of the liquid water in the tank it becomes clear that the implementation of separate phase balancing has only minor influence on the global behavior of the component. Therefore, the model might be reduced using only one lumped state into account. This state will be in the wet steam region during proper operation of the tank, i.e. $0 \leq$ level level $_{\text {max }}$ :

Mass balance for both phases:

$\operatorname{der}(M)=$ in.m+out.m;

Energy balance for both phases:

$\operatorname{der}(\mathrm{H})-\mathrm{V} * \operatorname{der}(\mathrm{p})=$ in. $\mathrm{w} * \mathrm{~h}_{-}$in +

out.w*h_out ;

With boiling vapor at the outlet of the liquid phase interface:

h_out=hls

The reduced model shows - as stated - similar transient behavior concerning mass storage, see figure 7 . In contrast to this, a different time development of the tank pressure has to be stated. The steady-state value is slightly lower for the simplified model and differs during transients. However, the deviation is below $1 \%$ relative error for both transient time period and steady state and the pressure time derivatives show the same sign.

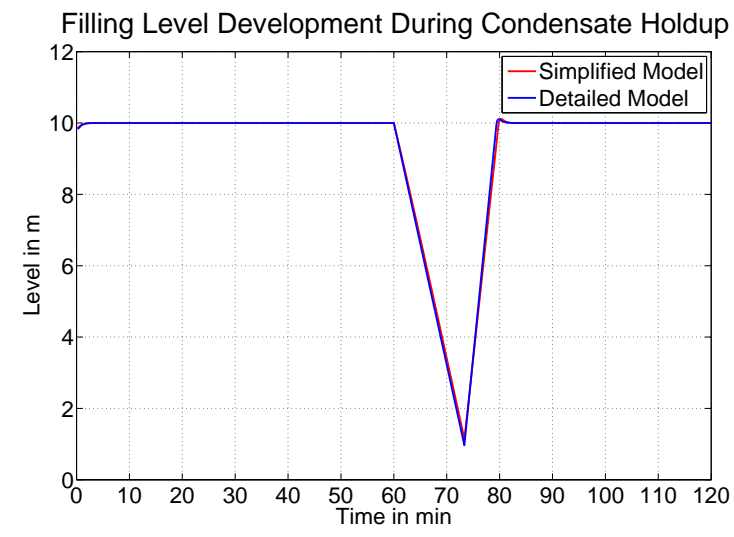

Figure 7: Filling level development during condensate hold-up applying different levels of detail

The effect of model simplification on the required condensate mass flow is shown in figure 9 and only small deviations must be stated. Thus, for controller design of the condensate pump the simplified model may be sufficient. 


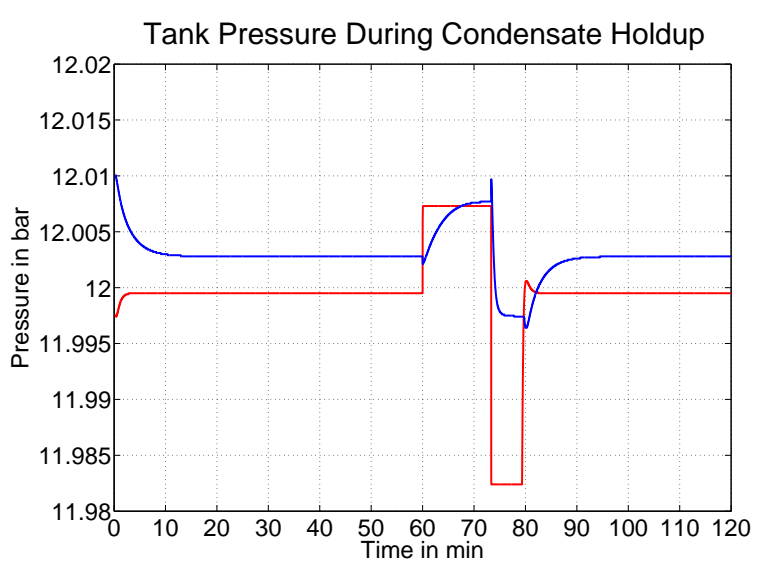

Figure 8: Tank pressure development during condensate hold-up applying different levels of detail

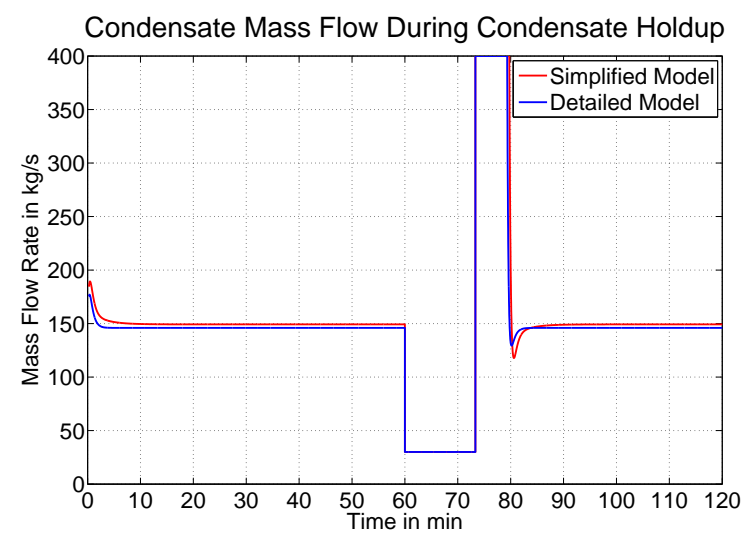

Figure 9: Condensate mass flow devepment during condensate hold-up applying different levels of detail

The mentioned deviations of the tank pressure for the detailed and simplified model may induce differing tapping mass flows. Tappings are controlled or fixed steam extractions providing steam from the turbines for heating of the low pressure preheaters and the feedwater tank. If the tapping valve is not controlled the corresponding mass flow rate is defined by the pressure states in the turbine and the low pressure path. Thus, the heating mass input may differ between both models requiring different condensate mass flows. In the consequence the effective turbine mass flow in the low pressure turbine stages is different when integrating the tank models in a complete steam cycle. Considering a conservative estimation in a scenario of $80 \%$ relative load this results in approx. $2 \%$ relative error of the generator power.

Comparing the models presented both, advantages and drawbacks, apply to each of the model approaches. The detailed model considering two different phases promises better numerical stability and more realistic results, especially during short-term transients while the simplified model is easier to initialize and will need less computational effort. Testing the convenience of the models under different usage conditions with respect to initialization and simulation progress will be a subject item of future investigations.

\section{Validation of the Model}

In order to check the created model on correctness, comparative measurements have been recorded in the power plant Rostock, which are shown below in contrast to the results of the simulation.

In the investigated period of time the power plant begins operation after 37 hour shutdown period with two subsequent positive load changes up to 95 percent. The development of the desired net power shown in figure 10 is the input to the model and is processed by the control system to a desired firing power signal and subsequently transfered to the coal mills and oil burners. Despite the simplifications in the reproduced control system of the power plant model a good reproduction could be achieved, differences between the model and measurement could be caused by parameter changes of the process, especially during a start, like a drifting heating value, uncertainties in the mill dynamic or degradation of the heating surfaces.

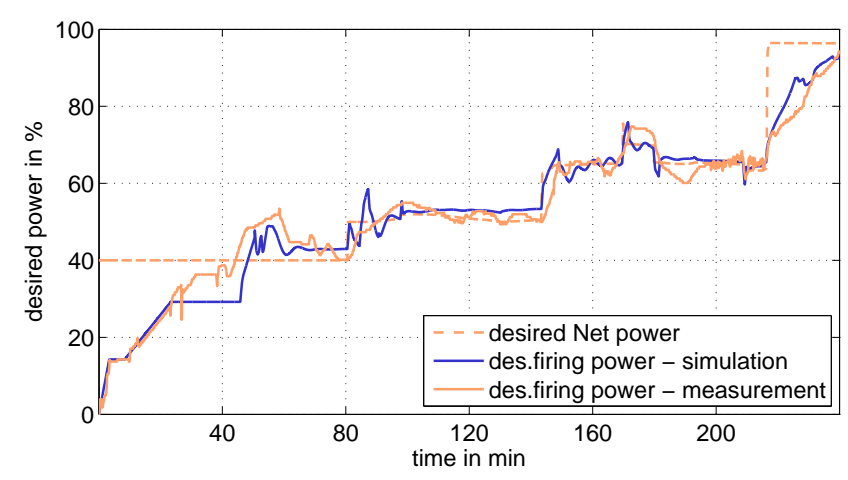

Figure 10: Definition of validation setup - power request from the load dispatcher and corresponding desired firing power

Beneath the power request the plant model needs two additional inputs, the state of the condensate water, which is provided by a load dependent table and the composition of the used coal. Since coal is not an homogeneous fuel the mass fraction of containing ash and water of the modeled coal are fluctuating in random intervals by $+/-1 \%$. All other boundary conditions for the model, like furnace outlet and condenser 
pressure as well as air inlet temperature have constant values.

Since the dynamic behavior of the overall process is mainly dominated by the fuel pulverization in the coal mills and the transient response of the boiler, it would be beneficial to validate the sub models for those two systems independently. But this is not possible, because the measurement of the system response of the coal mills, the coal dust mass flow rate upstream of the burners, is only possible with high efforts and low accuracy. Thus, such a measurement system is not standard and is not available. In a consequence, validation of the overall model is conducted by the use of the steam properties in the boiler and the generator output.

The live steam pressure and mass flow arise from the current heating by the furnace and the cooling from the working medium due to the feed by the feedwater pump. In figure 11 simulated and measured pressures at outlet of the boiler are compared. After 50 min the power plant is in sliding pressure operation and the life steam pressure is changing proportional with the load. In general a good conformity of both graphs can be stated. Variations (e.g. between 40 and $70 \mathrm{~min}$ ) could be explained with differences in the firing power. Considering this, a good reproduction of the hydraulic characteristic can be stated.

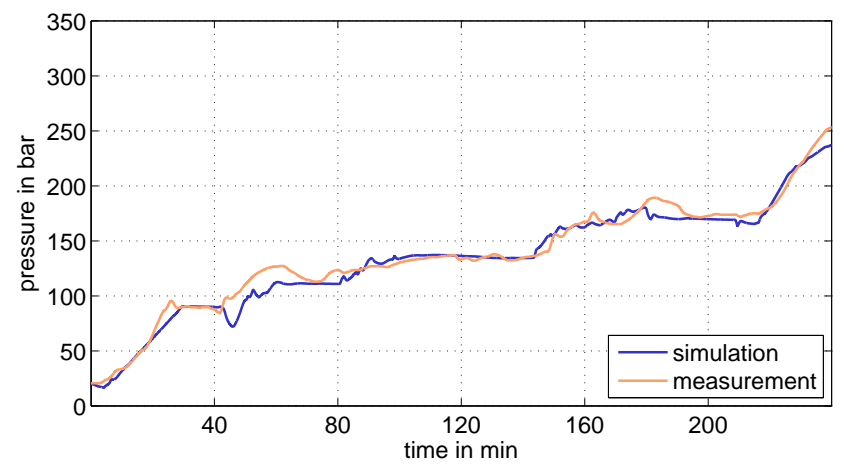

Figure 11: Comparison of calculated and measured life steam pressure at the boiler outlet

In figure 12 the development of the boiler inflow (Eco in) and outflow (life steam) mass flow rate is shown. In the first $50 \mathrm{~min}$ the boiler is in circulation mode and a minimum amount of $143 \mathrm{~kg} / \mathrm{s}$ of feedwater is entering the economizer and the unevaporated water fraction is separated after the evaporator and looped back to the boiler inlet. Then the power plant switches to Benson operation and the feed water as well as the life steam mass flow rate is proportional to the load.

In order to verify the proper representation of the

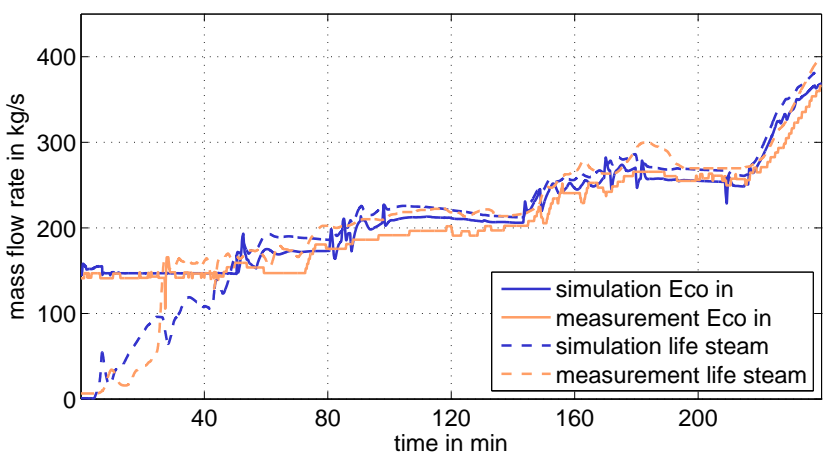

Figure 12: Comparison of calculated and measured economizer in and superheater out mass flow rate

heat transfer from the exhaust gas to the different heating surfaces by the model, the calculated steam temperatures at the outlet header of each heating device are compared to the corresponding measurement. In the following some representative plots are discussed. In figure 13 the water temperature entering the boiler at the economizer inlet and the steam temperature after the evaporator is brought out with respect to time.

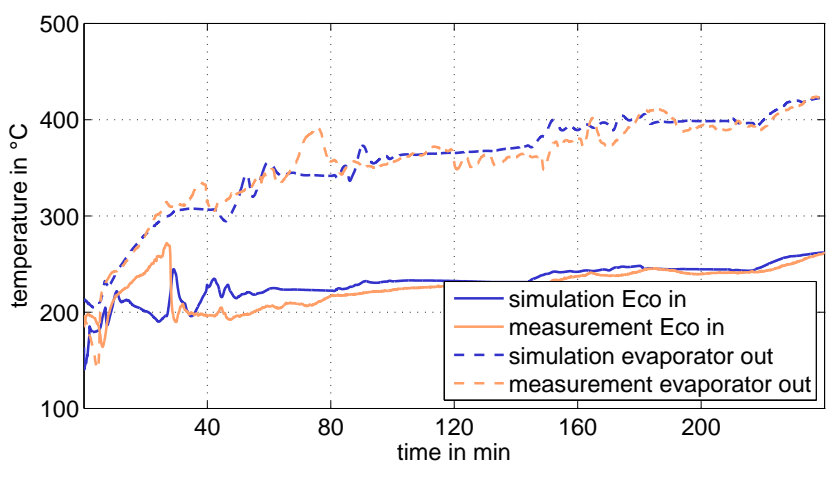

Figure 13: Comparison of calculated and measured fluid temperature at inlet of the economizer and after evaporator

Whereas the simulated evaporator outlet temperature shows a good agreement with the measurement the mean relative error is about $3.3 \%$, the economizer inlet temperature shows a deviation between 10 and 30 min with a maximum error of $28 \%$. This is caused by a difference in the circulation rate: in the simulation a large quantity of cold feed water is lowering the eco inlet temperature in contrast to the measurement. This means that a higher amount of almost boiling circulated water, as can be seen in figure 12 as the difference of the eco in and life steam flow, is leading to a high eco inlet temperature. In Benson operation the error is less than $5.2 \%$ and shows a very good correlation.

The trend of the temperature after superheater SH 1 
shows analogue results, hence the furnace and heat transfer model is capable to reproduce the heat transfer of the boiler and its temporal behaviour (see figure 14).

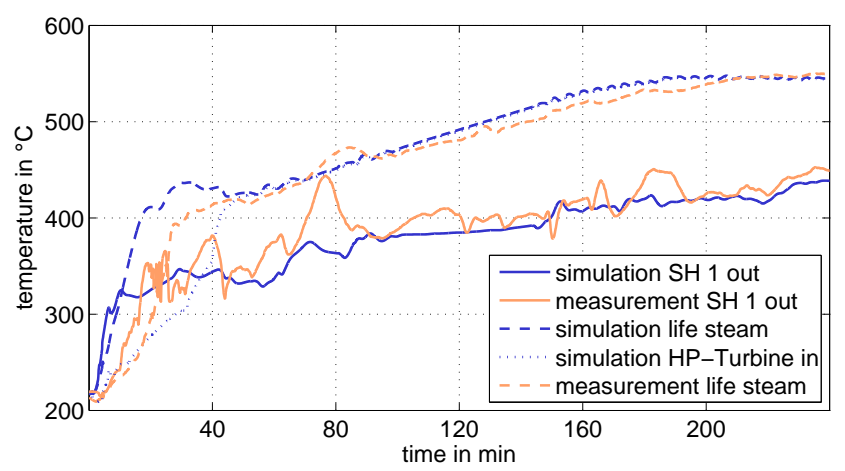

Figure 14: Comparison of calculated and measured steam temperatures after the first and the last superheater

In the same diagram the simulated and measured live steam temperatures are plotted. During the first phase of a start with low flow through the life steam pipes to the turbines, an inhomogeneous temperature distribution and the unknown location of the sensor complicates a validation, but the measurement is within the model temperatures at the in- and outlet of the life steam pipe.

During sliding pressure operation again a very high correlation between simulation and measurement can be stated. This can only be achieved by copying the cascaded PI-controller of the spray attemperators, that ensures the right tempering of the live steam.

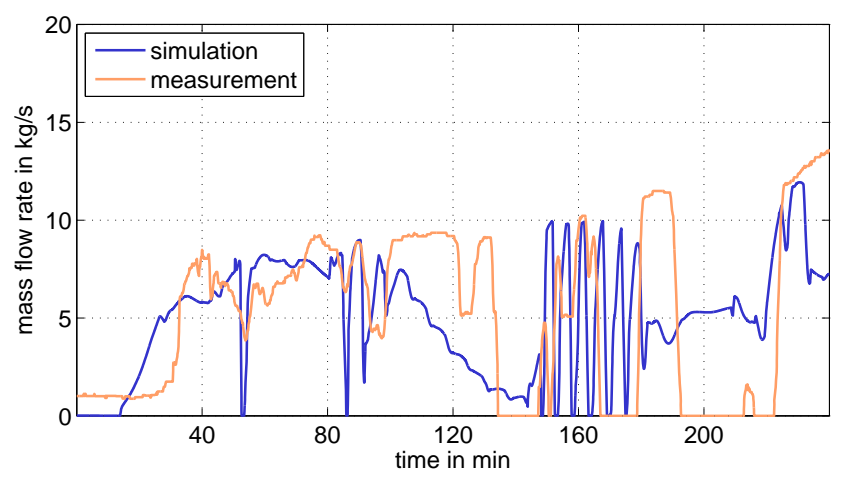

Figure 15: Comparison of calculated and measured injection mass flow rates at the first HP-injector (after first superheater)

Figure 15 shows the comparability of the implemented temperature control by comparing the simulated and measured injection mass flow rates. Both measured and simulated injection flow rates agree qualitatively very well and show similar dynamics.

The figure shows that the attemperator is operated at its limits which leads to quite extreme changes of valve opening between fully opened and fully closed. This behavior is uncritical, since the task of the first injector is it to keep the second injector within its proper operation limits.

As can be seen in figure 16 the net generator power, whose behavior is effected by the dynamics of the entire power plant process, shows a good correlation. Thus, it can be stated, that the dominating and relevant effects are reproduced by the model and the validation shown above approves the accuracy and the validity of the model assumptions.

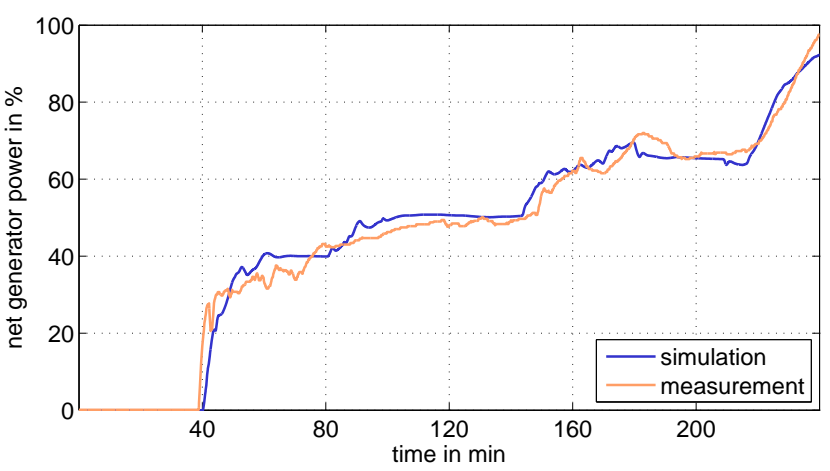

Figure 16: Comparison of the simulated net generator power and corresponding measurement

\section{Evaluation of Component Strain}

With this existing model it is possible to predict temperatures and temperature gradients at points which are inaccessible to measurements like wall temperatures of highly stressed components.

For the first 90 min of the presented soft start the occurring wall temperatures of the superheater outlet header are displayed in figure 17. Obviously the metal temperature at the outside of the wall follows the inner temperature with a certain delay and its amplitudes are considerably smaller. This effect can be explained with time specifics of the heat conduction and energy storage. The noticeable phase shift of the temperatures leads to relative high temperature differences between the inner and outer fiber in case of sharp edged changes in evaporator heating or cooling.

The evaluation of metal temperatures offers the possibility to benchmark different controller parameter sets with a view to preserving operation at concurrently high load dynamics. 


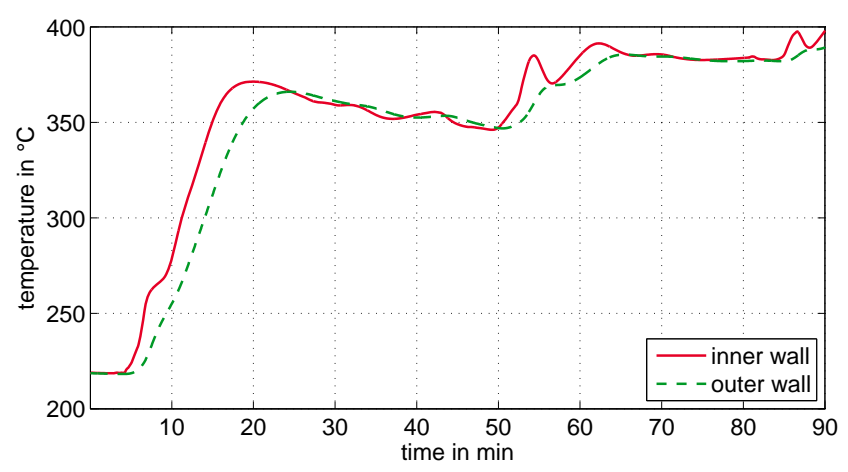

Figure 17: Metal temperatures in the superheater SH 2 outlet header

Quantification of the effects of thermal stress on the different components of a plant is a challenging task as the processes of fatigue are complex and highly statistical. For this reason the results of a fatigue prediction in this context can only be of qualitative nature and should be understood as a trend indicator that is capable of identifying the most stressed components and predict possible side effects of innovative control strategies on this complex system. For a detailed investigation of certain components a FEM-analysis should be carried out considering the installation situation (and with it possible pretensions in the component) and the exact geometry.

However, for a first estimation of the effects of more dynamic plant operation in the future two different approaches are used and should be discussed in the following:

The guidelines of the Deutsche Dampfkesselausschuss (2000) TRD 301 [8] and 508 [9] give directives for the estimation of fatigue of thick-walled boiler components under smouldering pressure and temperature due to start-up processes. For this purpose an effective stress range is evaluated with a Wöhler diagram for crack initiation. The following equation gives the law for calculating the stress range $\Delta \sigma$.

$$
\Delta \sigma_{i}=\left(\alpha_{m} \frac{d_{m}}{2 s_{b}}\right) \Delta p+\left(\alpha_{\vartheta} \frac{\beta_{L \vartheta} E_{\vartheta}}{1-v}\right) \Delta \Theta
$$

Herein $\alpha_{m}, \alpha_{\vartheta}, d_{m}, \beta_{L \vartheta}, E_{\vartheta}, v, \Delta p$ and $\Delta \Theta$ denote for mechanical and thermal correction factor for stress superelevation at branches, mean diameter, mean wall thickness, linear expansion coefficient, Young's modulus, Poisson's ratio and the range of pressure and temperature difference during load change, respectively. Figure 18 shows qualitatively the evaluation of the working stress during load change. The maximum number of load changes comparable to the actual one is generated from the Wöhler-curve. The percentile fatigue of the actual load change is then:

$$
e=\frac{1}{N} 100
$$

This estimation leads to conservative results in order to handle the numerous uncertainties in calculation of working stresses at complex components and material properties.

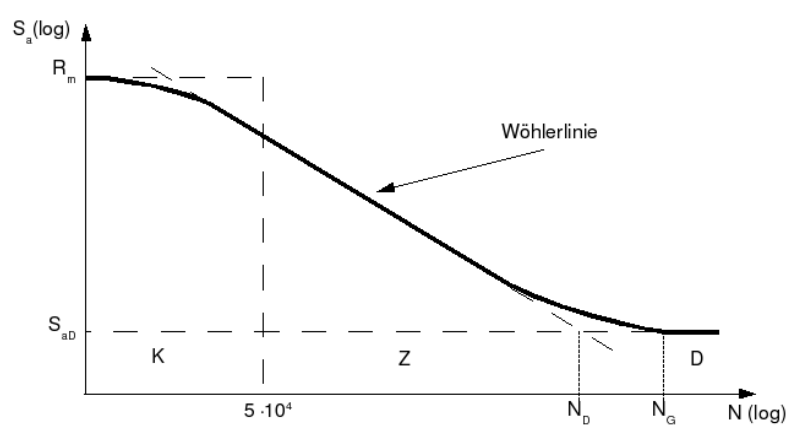

Figure 18: Principle of evaluation of component stress for cyclic loading [11].

This method allows to benchmark different operation modes in terms of their level of deterioration to different components. In figure 19 the fatigue of a soft start and several load changes is plotted for the inlet and outlet headers of the superheaters and reheaters. Please note that currently normal operation is between $50 \%$ and $100 \%$ load, so the shown load change of $60 \%$ could be considered as an unconventional operation.

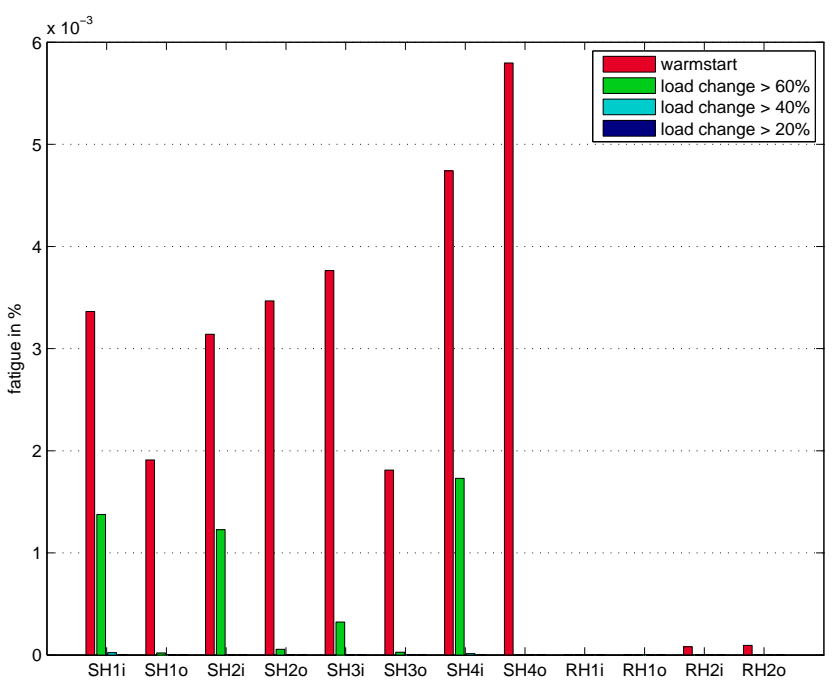

Figure 19: Fatigue of heating surface in- and outlet headers for different base stress situations 
It can be obtained, that the outlet header of superheater SH 4 is effected the most, whereas the headers of the reheaters are not or lowly stressed. Furthermore it can be derived, that load changes less than $40 \%$ barely cause any fatigue, because the stress levels are below the endurance strength.

Considering the flaw growth of predamaged component gives a far more sensitive view on the operation mode. The German Forschungskuratorium Maschinenbau [10] gives guidelines for the calculation of crack progress. Figure 20 gives a general overview on crack propagation rate as function of the range of stress intensity factor $\Delta K$.

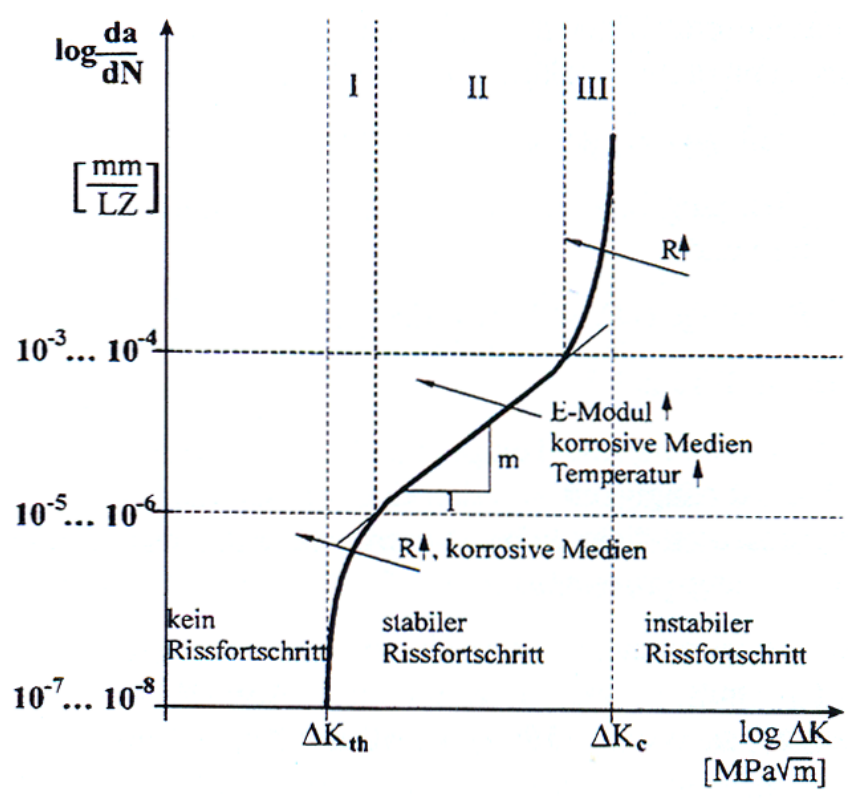

Figure 20: Overview on crack propagation under cyclic load [10].

According to figure 20 there is a certain load that does not leads to crack propagation $\left(\Delta K \leq \Delta K_{t h}\right)$. In region I to III there is a stable propagation to be expected $\left(\Delta K_{t h} \leq \Delta K \leq \Delta K_{c}\right)$ which can be conservatively estimated by the law of Paris and Erdogan:

$$
\frac{d a}{d N}=C \Delta K^{m}
$$

Where $a, N, C, m$ denotes for crack length, number of cycles, a case-specific factor and a load specific exponent, respectively. The stress intensity factor has to be calculated depending on the flaw's geometry and size and its position within the component. With this tool it is possible to detect the most strained components by comparing the crack growth over a certain reference time period.

In an analogue manner as in figure 19 the flaw propagation is shown for thick-walled headers in figure 21 .

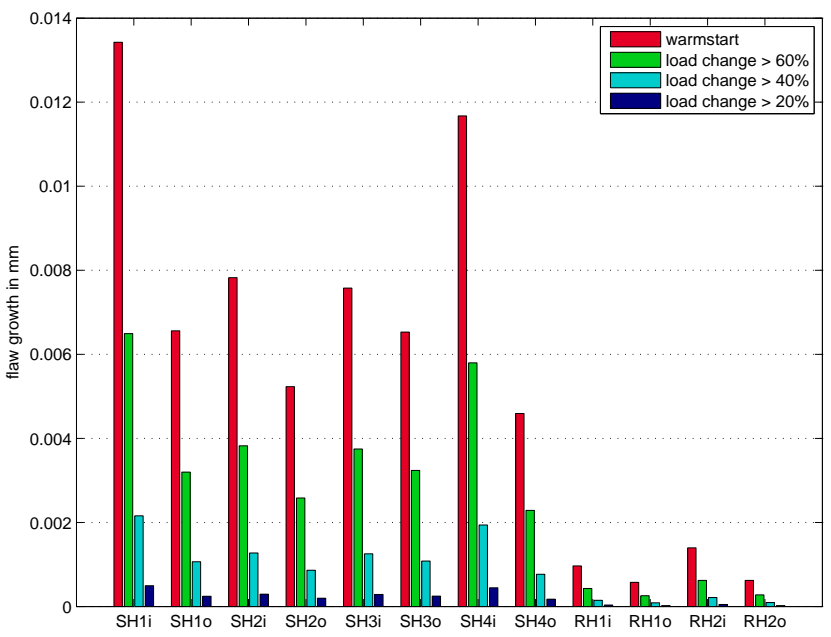

Figure 21: Flaw growth in potentially pre-damaged thick-walled in- and outlet headers for different base stress situations

In contrast to the fatigue also low stress levels of small load changes cause impairment and consequently with this estimation a method is given to evaluate the deterioration potential of normal operation.

\section{Conclusion and Outlook}

A detailed model of a coal-fired power unit has been implemented and extensively validated. The model makes use of the open-source Modelica library ThermoPower. A number of components especially for modeling of start-up-specific components, like the cyclone separator and the start-up bottle as well as models for the description of the fuel conversion and heat transfer in the firing of the plant have been implemented.

As an example for an application of the developed model some base operation scenarios, like load changes and a soft start, have been evaluated in terms of life time consumption. In a next step the influence of increased load gradients will be investigated.

The modular structure of the model allows the easy replacement of single components, e.g. life steam temperature control, which enables the benchmark of advanced control systems or the implementation of different or additional hardware for different operation scenarios. In this way, future demands on power plants, which might become necessary in order to realize wind integration successfully at controllable costs, can be benchmarked. This aspect of power plant operation management will probably become more important due to highly increasing wind power production 
and its fluctuating characteristic.

The detailed manner of the plant model does not allow long term simulation over years or even weeks due to high computing time at this actual state of development. Therefore the fatigue has to be extrapolated in a first step assuming a constant or a repetitive operation mode for a long time period. Future work could cover a model reduction to increase its efficiency.

\section{References}

[1] Dahl-Soerensen, M.J./ Solberg, B. Pulverized Fuel Control using Biased Flow Measurements. In: IFAC Symposium on Power Plants and Power Systems Control, Tampere, 2009.

[2] Hojczyk,B./ Hühne,W./ Thierfelder,H.G. Das Steinkohlekraftwerk Rostock. In: VGB Kraftwerkstechnik 77, 1997.

[3] Casella,C./ Leva,A. Open Library for Power Plant Simulation: Design and Experimental Validation. In: proceedings of 3rd. International Modelica Conference, Linköping, 2003.

[4] Niemczyk,P./ Andersen,P./ Bendtsen,J.D. /Soendergaard Pedersen,T. /Ravn,A.P. Derivation and validation of a coal mill model for control. In: IFAC Symposium on Power Plants and Power Systems Control, Tampere, 2009.

[5] Effenberger Dampferzeugung. Berlin, SpringerVerlag, 2000.

[6] Verein Deutscher Ingenieure VDI-Wärmeatlas, 10. Auflage. Berlin, Springer-Verlag, 2006.

[7] VDI/VDE-Gesellschaft Mess- und Automatisierungstechnik VDI/VDE - Richtlinie 3508: Block-Führung/-Regelung von Wärmekraftwerken, 2002.

[8] Deutscher Dampfkesselausschuss Technische Regeln für Dampfkessel (TRD) 301 Berechnung auf Wechselbeanpruchung durch schwellenden Innendruck bzw. durch kombinierte Innendruckund Temperaturänderungen. Carl Heymanns Verlag KG, 2000.

[9] Deutscher Dampfkesselausschuss Technische Regeln für Dampfkessel (TRD) 508 Zusätzliche Prüfungen an Bauteilen berechnet mit zeitabhängigen Festigkeitswerten. Carl Heymanns Verlag KG, 2000.
[10] Forschungskuratorium Maschinenbau Bruchmechanischer Festigkeitsnachweis für Maschinenbauteile. VDMA-Verlag, 2001.

[11] Lewin,G./ Lässig, G./ Woywode,N. Apparate und Behälter: Grundlagen Festigkeitsrechung. Berlin, Verlag Technik, 1990. 